\title{
FRUTOS DE DIAGONALES
}

\author{
DIAGONAL FRUITS
}

Lucía Álvarez | luciaalvarezpintado@gmail.com

Daniel Lorenzo | danielllorenzo@gmail.com

Marina Panfili | marinapanfili@gmail.com

Juan Cruz Pedroni | pedronijuancruz@gmail.com

Facultad de Bellas Artes. Universidad Nacional de La Plata. Argentina

Recibido: 9/3/2018 | Aceptado: 14/7/2018

\section{RESUMEN}

En 2017 comenzamos un proyecto de investigación sobre las artes visuales en la ciudad de La Plata desde la década de 1960 hasta la actualidad. Caminamos por las calles, realizamos encuentros, imaginamos metáforas para un proyecto, en esencia, inmaduro. A partir de entrevistas y del relevamiento bibliográfico y documental, generamos una visualización de datos interactiva. En marzo de 2018 dimos a conocer el proyecto Accidentes geográficos, periplos y otras vicisitudes del arte platense (un atlas verde). El verde indica la inmadurez como condición de posibilidad. Este ensayo está escrito a la deriva de estos acontecimientos y es una aproximación poética a algunas ideas que emergieron.

\section{PALABRAS CLAVE}

Artes visuales; atlas; La Plata

\section{ABSTRACT}

In 2017 we started a research on the visual arts in the city of La Plata, from the 1960 s to the present. We walk the streets, hold meetings, and imagine metaphors for a project, in essence, immature. Based on interviews and the bibliographic and documentary survey, we generate an interactive data visualization. In March 2018 we announced the project Geographical accidents, journeys and other vicissitudes of platense art (a green atlas). Green indicates immaturity as a condition of possibility. This essay is written to the drift of these events and becomes a poetic approach to some ideas that emerged.

\section{KEYWORDS}

Visual arts; atlas; La Plata 


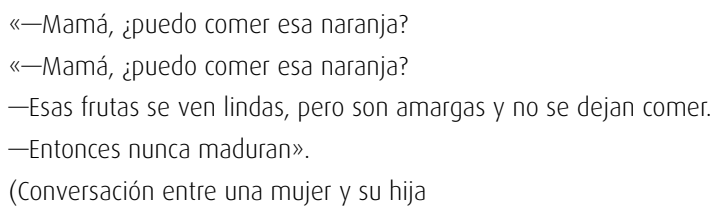

Según un censo oficial de especies del año 2010, la ciudad de La Plata cuenta con 460 naranjos amargos como parte de su arbolado urbano. Históricamente, esta especie se cultivó como árbol ornamental; sus frutos se pueden utilizar para la producción de dulces. Sin embargo, si un paseante desprevenido arranca un fruto y lo prueba, en el primer bocado sentirá un gusto tan amargo que, probablemente, desista de la cosecha callejera.

\section{FLORES DE AZAHAR}

Cada árbol, en primavera, produce un gran número de flores. Solo algunas cuajan y producen frutos. El aroma a azahar invade las calles de la ciudad. Cuando comenzamos esta tarea de investigación y la flor-otlos verde estuvo a punto de cuajar, nos preguntamos ¿por dónde empezar a trazar un atlas del arte platense? En un proyecto con una escala tan ambiciosa, la pregunta podía ser inhibitoria. Decidimos no responderla, o contestar de manera evasiva y empezar - guiados por nuestro olfato- por cualquier punto, por la primera calle que parecía conducirnos a un parque. La decisión nos llevó lejos de los puntos de partida mejor señalizados, de las obras que acontecieron con la aspiración de ser un comienzo; en definitiva, de las declaraciones de un principio que son, también, declaraciones de principios. Pero, sobre todo, nos permitió empezar: funcionó como un principio operativo. Tal vez porque habitamos una ciudad llena de diagonales, creemos que entrando por cualquier parte podemos llegar a cualquier otra de manera más fácil, con menos prejuicios y, a lo largo de esa trayectoria no planificada, sentir la textura de cada relación. Encontrar plataformas colaborativas, formas específicas de asociación en torno a un taller, una revista o una sala de exposiciones, pero, también, relaciones de subordinación, de conflicto o de segregación. 


\section{PERDERSE EN EL FOLLAJE}

Los naranjos son pequeños, en su edad madura llegan a medir entre tres y cinco metros. Aunque la mayoría de las veces es fácil obtener los frutos con solo estirar el brazo, decidimos buscar formas de meternos en el follaje para situar la mirada desde otro punto de vista. Diversificamos estrategias de investigación, tomamos algunas metodologías más clásicas y otras menos definidas que trajimos de ámbitos domésticos e íntimos. En cualquier caso, no teníamos claro cómo llevarlas adelante. Consultamos lo que artistas, periodistas e historiadores del arte escribieron antes que nosotros sobre La Plata. Buscamos y revisamos libros, revistas y publicaciones locales y nos centramos en aquellas que historizan y describen momentos clave de las artes en la ciudad [Figura 1]. Asimismo, acudimos a la consulta de fuentes primarias escritas, lo que se entiende generalmente por documentos. Aunque tratamos de ser exhaustivos, consideramos que solamente recolectamos una pequeña parte de los textos disponibles. Sería deseable, de todos modos, que el atlas siga cargándose con las naranjas dispersas por ahí para que pueda ser leído tombién como un estado de la bibliografía.

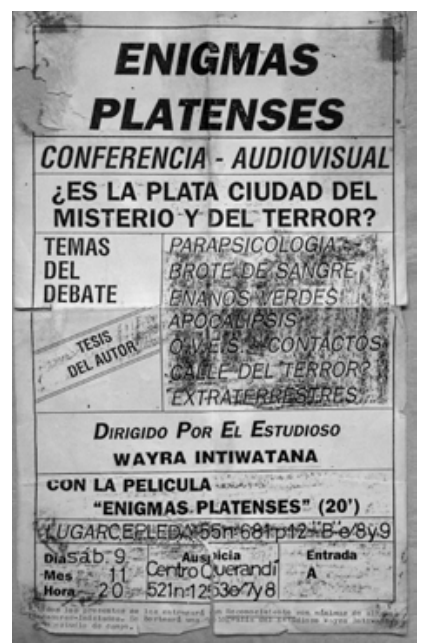

Figura 1. Afiche de la conferencia y proyección audiovisual Enigmas Platenses (1990), realizada por Wayra Intiwatana. Archivo Marcelo Metayer

Continuamos este periplo con una cena de artistas de la ciudad que nos podían contar cómo había sido la escena de las artes visuales en La Plata durante la década del noventa. Siempre incompleta y sin pretensión de completitud, la convocatoria citó a doce protagonistas, algunos afines en poéticas y perspectivas, otros no tanto. 
Una de las artistas invitadas nos recibió en su casa; los organizadores llevaríamos la comida pero todos terminaron aportando y el trabajo de campo fue un banquete. La consigna era comer, beber, charlar, rememorar y, sobre todo, nombrar: traer al presente a personas, actividades y espacios. Antes de comenzar imaginábamos que el follaje no dejaba ver algunas cosas y así fue. Luego de una conversación polifónica y caótica de cuatro horas, la información desbordó la posibilidad de un mapa. Habíamos llevado papelógrafos para graficar un diagrama colectivo, pero la mesa estaba tan llena de comida que tuvimos que pegarlos sobre una puertaventana, una especie de gran vidrio. Cuando nos fuimos, los papeles quedaron en blanco como huella de la reunión. Eran una pregunta que no se terminaba de formular; no se trataba tanto de cómo representar, sino del deseo y de la posibilidad misma de una representación. Había que ver si queríamos detenernos en los árboles o transitar la tupidez sin forma.

\section{NUNCA POR LAS RAMAS}

A medida que recorrimos y trepamos los diferentes naranjos de la ciudad, los datos comenzaron a ser cada vez más incontenibles. Entendimos que debíamos (des)organizar tanta información y elegimos la red como forma de antigenealogía, para complicar la difundida imagen en la que el arte de La Plata tiene que tener una vinculación necesaria con Edgardo Antonio Vigo o con Emilio Pettoruti. No nos interesa negar estas figuras focales sino pensar otras. También, la elección está motivada por una preocupación por la dimensión espacial que creemos que tanto la red como el atlas nos ayudan a graficar. La red nos permite encontrar distintas configuraciones según lo que busquemos en ella: dinámicas colaborativas en una cantidad de proyectos, circuitos, relaciones inesperadas, pero, además, asimetrías y concentraciones de energía en determinadas zonas del mapa.

Fue entonces que elegimos utilizar una herramienta digital para organizar y visualizar el Atlas Verde en forma de red. ${ }^{1}$ A principios de 2018, fuimos invitados para participar en Lo que cabe en las historios, una muestra curada por Guillermina Mongan en el espacio Ramos Generales de La Plata, que intentaba dar cuenta de los diferentes proyectos y perspectivas historiográficas locales. En esa ocasión presentamos por primera vez el fruto-atlas verde. En un escritorio, montado en la vereda, dispusimos una pantalla en la que se podía interactuar con la plataforma. Sobre la misma mesa dejamos una suerte de fichas en las que cada asistente podía escribir nombre y tipo de entidad que deseaba agregar al mapa. También, podían incorporar relaciones entre nodos ya ingresados. La carga compulsiva generó una cantidad creciente de información que se sumaba a los datos del banquete y a los que espigamos, después,
1 Puede verse en el siguiente enlace: https://onodo.org/visualizations/30203 
entre los documentos. Unos y otros se intensificaban con las asociaciones de una memoria en red. El resultado es una imagen de saturación que, a primera vista, se hace difícilmente legible. Teníamos datos para hacer dulce, nunca habríamos podido planificar semejante visualidad. De manera retrospectiva podemos volver sobre lo que hicimos sin estar seguros del procedimiento que seguíamos.

Así se va (des)componiendo este atlas. Componer y no completar. No dar por supuesto un recipiente a ser llenado, sino vinculaciones que van definiendo su propio espacio a medida que crecen. La multiplicación de nombres en la red desafía los relatos - nuestros y ajenos- hace más difícil afirmar la existencia de algunas relaciones como algo evidente y directo, permite imaginar matices, construir historias con mayores inflexiones, donde caben más intermediarios y donde cada nueva línea hace un trazado contingente y parcial. Otro efecto que se desprende de la población aumentada de puntos -y esto tampoco es algo calculado- tiene que ver con que se pone en suspenso el lugar protagónico de los nombres individuales. Por contrapartida, entre tantos naranjos de brotes Iustrosos, lo que de a poco va saliendo a la superficie como resultado de un aroma o de una textura, son los modos de relación: formas colectivas de producción, puentes entre distintos tiempos, estaciones casi obligatorias para la trayectoria de un artista en un determinado momento. Pero para nosotros el atlas es, ante todo, una máquina narrativa. Un barco con los depósitos llenos de naranjas para hacer dulce lanzado a lo incalculable.

\section{COSECHAR LO INMADURO}

Como dijimos más arriba, lo que el atlas hace emerger de manera más interesante quizás sean las relaciones y no tanto los nombres per se. De todos modos, también creemos que se trata de conservar, de salvar del olvido cosas - sin saber bien por qué ni para qué-. Tal vez, por el solo hecho de haber existido merecen que las rescatemos. Siempre creyendo que de forma tardía ese nombre puede volver a aparecer como potencia para ampliar relatos. Para hacerlos menos directos, para que las asociaciones sean menos el resultado de una línea ya trazada que la propagación por acodos e injertos.

En tiempo de cosecha, siempre es bienvenido tener alguna forma provisoria de organización. Por eso, entrando en esta etapa, nos atrevemos a trazar algunas líneas de trabajo heterogéneas -líneas que todavía debemos ver si funcionan-. Improvisamos un índice con categorías que consideramos que emergen del mapa inestable y cambiante que tenemos hasta el día de hoy. Y de los relatos, no del todo articulados, que se tejieron a su alrededor: 
- Bares, cafés y otros espacios de sociabilidad artísticos.

- Espacios de formación alternativos / por fuera de la academia.

- Espacios de exhibición en los umbrales / residuales / márgenes topográficos.

- Geografías poéticas platenses: prácticas que poetizaron la ciudad.

- Reuniones y complicidades. Grupos y colectivos.

- Chismografía. Robo, copia, la presencia de los grandes maestros en la ciudad.

- Historia de un fracaso rotundo: galerías y venta de obra en La Plata.

- Relación con Buenos Aires: intervenir desde La Plata.

- Historia de la pulsión salonera.

- Baldíos y ruinas del arte platense: bibliotecas y museos. Burocracia y activismo.

- Administración pública y práctica artística: la dialéctica oculta.

Estos copítulos, en el mejor de los casos, salen de un croquis que tiene algo que ver con La Plata. Retienen alguna señal de ese territorio que sale a interpelar el gesto del que pretende cartografiarlo. Si no resultan los mapas más acertados, nos gustaría pensar que esa falla es un resto ingobernable de deseos y de utopías que también componen la ciudad.

Como le explicó a su madre la niña sabia: el atlas, como la naranja de calle 47, está destinada a su inmadurez. Su incompletitud es constitutiva no por un carácter inabarcable sino, ante todo, porque no creemos que haya algo a completar.

\section{REFERENCIAS}

Atlas verde. (2018). Acerco de. Recuperado https://onodo.org/visualizations/30203

AA. VV. (marzo de 2018). Lo que cabe en los historias [exposición colectiva]. Ramos Generales, La Plata, Argentina.

El Día. (27 de agosto de2012). Los árboles frutales de la ciudad se miran, pero no se comen. Recuperado de https://www.eldia.com/ nota/2012-8-27-los-arboles-frutales-de-la-ciudad-se-miran-pero-no-se-comen

Intiwatana, W. (noviembre de 1990). La Ploto, 1990 [afiche de la conferencia y proyección audiovisual Enigmos Platenses]. La Plata, Argentina: Archivo Marcelo Metayer. 